\title{
Comunicação
}

[Communication]

\section{Sensibilidade antimicrobiana de cepas de Staphylococcus spp. isoladas de carcaças de frango comercializadas em Recife}

[Antibiograms of Staphylococcus spp. isolates from chicken carcass in Recife, Brazil]

\author{
M.F.L.Freitas ${ }^{1}$, R.A. Mota ${ }^{2}$, A.E.D.S. Leão $o^{3}$, M.L. Figueiredo $o^{3}$, M.M. Fonte ${ }^{3}$, R.F.C. Vieira ${ }^{3}$ \\ ${ }^{1}$ Médica Veterinária \\ Rua Prof. Marculino Botelho, 600 / 702 B, Casa Caiada \\ 53130-150 - Olinda, PE \\ ${ }^{2}$ Universidade Federal Rural de Pernambuco - Recife, PE \\ ${ }^{3}$ Aluno de graduação em Medicina Veterinária da UFRPE
}

A evolução e a disseminação de microrganismos resistentes aos antibióticos são o resultado da pressão selecionadora imposta pelo homem, seja pela prescrição necessária dessas drogas ou pelo uso incorreto em tratamentos sem diagnóstico estabelecido, automedicação, desperdício de restos de antimicrobianos no meio ambiente e emprego desses fármacos como fatores de crescimento em animais de produção (Tavares, 2000). De acordo com Smith (1974), é possível que os resíduos de antibióticos em produtos animais possam ser veiculados a pessoas que os consumam, produzindo efeitos de toxicidade ou reações alérgicas em indivíduos previamente sensibilizados, além de favorecer o aparecimento de bactérias resistentes.

O desenvolvimento de resistência por certas bactérias patogênicas é mais rápido que a capacidade da indústria para produzir novas drogas. Entre as bactérias que voltaram a ser perigosas destaca-se o Staphylococcus aureus, um poderoso agente de infecção hospitalar (Souza, 1998). Diante do panorama de resistência bacteriana e de sua importância para a saúde pública, este estudo teve como objetivo traçar o perfil de sensibilidade antimicrobiana de Staphylococcus spp., isolados de carcaças de frango comercializadas na cidade do Recife, frente a vários antibióticos.
Foram analisadas 61 carcaças de frango entre outubro de 2001 e abril de 2002, sendo 30 amostras in natura, sem marca, adquiridas em seis mercados públicos e 31 amostras resfriadas, de cinco marcas, adquiridas em sete supermercados, localizados na cidade do Recife. As amostras foram enviadas ao laboratório, onde foram devidamente processadas para o isolamento de Staphylococcus spp., de acordo com a metodologia descrita por Siqueira (1995). Para a identificação do Staphylococcus aureus todas as cepas foram submetidas à coloração pelo método de Gram, produção de coagulase, catalase e DNAse (Koneman, 2001), capacidade de lisar hemácias de carneiro e de produzir ácido a partir de glicose (anaerobiose) e de manitol (aerobiose e anaerobiose) (Mac Faddin, 1980).

Noventa cepas de Staphylococcus spp., sendo 51 de Staphylococcus aureus e 39 de Staphylococcus coagulase negativa, foram submetidas a testes de sensibilidade antimicrobiana, utilizando técnica de difusão em disco (Bauer et al., 1966). O resultado dos testes de sensibilidade antimicrobiana ao Staphylococcus spp. frente a 17 antibióticos encontra-se na Tab. 1. O antibiótico mais eficaz foi a vancomicina e o menos a eritromicina.

Recebido para publicação em 30 de janeiro de 2003

Recebido para publicação, após modificações, em 19 de janeiro de 2004

E-mail:manu@veloxmail.com.br 
Tabela 1. Sensibilidade antimicrobiana de 90 cepas de Staphylococcus spp. isoladas e carcaças de frango in natura e resfriadas, comercializadas na cidade do Recife, PE

\begin{tabular}{lccccc}
\hline \multirow{2}{*}{ Antibiótico } & \multicolumn{2}{c}{ Sensível } & & \multicolumn{2}{c}{ Resistente } \\
\cline { 2 - 3 } \cline { 6 - 7 } & $\mathrm{N}^{\mathrm{o}}$ & $\%$ & & $\mathrm{~N}^{\mathrm{o}}$ & $\%$ \\
\hline Vancomicina $(30 \mu \mathrm{g})$ & 81 & 90,0 & & 9 & 10,0 \\
Cloranfenicol $(30 \mu \mathrm{g})$ & 78 & 86,7 & & 12 & 13,3 \\
Gentamicina $(10 \mu \mathrm{g})$ & 76 & 84,4 & & 14 & 15,6 \\
Cefalexina $(30 \mu \mathrm{g})$ & 70 & 77,8 & & 20 & 22,2 \\
Neomicina $(30 \mu \mathrm{g})$ & 64 & 71,1 & & 26 & 28,9 \\
Bacitracina $(10 \mu \mathrm{g})$ & 56 & 62,2 & & 34 & 37,8 \\
Oxacilina $(1 \mu \mathrm{g})$ & 56 & 62,2 & & 34 & 37,8 \\
Ciprofloxacina $(5 \mu \mathrm{g})$ & 55 & 61,1 & & 35 & 38,9 \\
Enrofloxacina $(5 \mu \mathrm{g})$ & 53 & 58,9 & & 37 & 41,1 \\
Norfloxacina $(10 \mu \mathrm{g})$ & 48 & 53,3 & & 42 & 46,7 \\
Amoxicilina $(10 \mu \mathrm{g})$ & 44 & 48,9 & & 46 & 51,1 \\
Clindamicina $(2 \mu \mathrm{g})$ & 43 & 47,8 & & 47 & 52,2 \\
Novobiocina $(5 \mu \mathrm{g})$ & 37 & 41,1 & & 53 & 58,9 \\
Lincomicina $(2 \mu \mathrm{g})$ & 33 & 36,7 & & 57 & 63,3 \\
Penicilina $\mathrm{G}(10 \mu \mathrm{g})$ & 28 & 31,1 & & 62 & 68,9 \\
Polimixina B $(300 \mu \mathrm{g})$ & 28 & 31,1 & & 62 & 68,9 \\
Eritromicina $(15 \mu \mathrm{g})$ & 23 & 25,6 & & 67 & 74,4 \\
\hline
\end{tabular}

A trabalharem com amostras de $S$. aureus isoladas de carcaças de frango e de equipamentos do abatedouro de aves, Manie et al. (1997) e Geornaras e Holy (2001) observaram que todos os isolados foram sensíveis à vancomicina, o que demonstra a eficiência desse antibiótico para tratamentos de infecções por estafilococos. Apesar da baixa ocorrência de resistência de Staphylococcus spp. à vancomicina, aproximadamente $10 \%$ das cepas, esse resultado é preocupante, pois ela é o medicamento humano mais utilizado para combater infecções hospitalares, principalmente as causadas por estafilococos resistentes ao grupo das penicilinas, incluindo oxacilina, meticilina e amoxicilina.

Adesiyun e Kwaga (1984) observaram que a resistência à eritromicina, um macrolídeo, só foi observada em cepas provenientes de frango assado. Segundo Tavares (2000), os estafilococos resistentes aos beta-lactâmicos penicilinases-resistentes (meticilina e oxacilina) freqüentemente mostram-se também resistentes aos macrolídeos, aminoglicosídeos, tetraciclinas e outros agentes antimicrobianos. Os resultados dos autores citados e os de Nawaz et al. (1999) condizem com os obtidos neste estudo. Este fato constitui uma alerta para o fato de a eritromicina, rotineiramente empregada no tratamento de doenças de aves, a longo prazo trazer conseqüências indesejáveis, como o desenvolvimento de Staphylococcus spp. resistentes à eritromicina.

Observou-se que $22,2 \%$ das cepas de Staphylococcus spp. apresentaram-se resistentes a cinco antibióticos, $12,2 \%$ a seis e $11,1 \%$ a 14 antibióticos. Esta elevada ocorrência de resistência múltipla a antibióticos apresenta um risco potencial para a saúde pública e pode dificultar o tratamento de doenças humanas e de animais, agravando quadros clínicos potencialmente curáveis (Sena, 2000). Um alto nível de resistência múltipla também foi observado em amostras de Staphylococcus spp. isoladas de carne de frango por Manie et al. (1997).

Palavras-chave: antibiograma, carcaça de frango, Staphylococcus spp.

\begin{abstract}
Antibiotic susceptibility of the Staphylococcus spp. isolated from chicken carcass from the city of Recife, Pernambuco, was determined. Out of 90 strains of Staphylococcus spp., 51 were classified as Staphylococcus aureus and 39 as Staphylococcus negative coagulase. Samples were submitted to the disc diffusion technique for the antibiotic susceptibility test. Among the 17 antibiotics tested, the most efficient was vancomycin. Twenty (22.2\%), 11 (12.2\%) and 10 (11.1\%) of the Staphylococcus spp. samples were resistant to five, six and 14 antibiotics, respectively.
\end{abstract}

Keywords: antibiogram, chicken carcass, Staphylococcus ssp. 


\section{REFERÊNCIAS BIBLIOGRÁFICAS}

ADESIYUN, A.A.; KWAGA, J.K.P. Antibiograms of Staphylococcus aureus isolates from same ready-to-eat products. J. Food Prot., v.47, p.865-867, 1984.

BAUER, M.D.; KIRBY, W.M.M.; SHERRIS, J.C. et al. Antibiotic susceptibility testing by a standardized single disk method. Am. J. Clin. Pathol., v.45, p.493-496, 1966.

GEORNARAS, I.; HOLY, A.V. Antimicrobial susceptibilities of isolates of Staphylococcus aureus, Listeria species and Salmonella serotypes associated with poultry processing. Int. J. Food Microbiol., v.70, p.29-35, 2001.

GOULART, C.S.; LOPES, C.A.M.; OYAN, P. Sensibilidade antimicrobiana de amostras de Staphylococcus coagulase positiva e negativa isoladas de otites externas de cães. In: CONGRESSO BRASILEIRO DE MICROBIOLOGIA, 20., 1999, Salvador. Anais... Salvador. p.157.

KONEMAN, E.W.; ALLEN, S.D.; JANDA. et al. Diagnóstico microbiológico - texto e atlas colorido. 5.ed. Rio de Janeiro: Editora Médica e Científica, 2001. 1465p.

MAC FADDIN, J.F. Biochemical test for identification of medical bacteria. 2.ed. Baltimore: Williams \& Wilkins, 1980. p.527.
MANIE, T.; KHAN, S.; BROZEL, V.S. et al. Antimicrobial resistence of bacteria isolated from slaughtered and retail chickens in South Africa. Lett. Appl. Microbiol., v.26, p.253-258, 1997.

NAWAZ, M.S.; KHAN, A.A.; KHAN, S.A. et al. Biochemical and molecular characterization of erythromycin-resistant avian Staphylococcus spp. isolated from chickens. Poult. Sci., v.78, p.1191-1197, 1999.

SENA, M.J. Perfil epidemiológico, resistência a antibióticos e aos conservantes nisina e sistema lactoperoxidase de Staphylococcus sp. isolados de queijos coalho comercializados em Recife-PE. 2000. 75f. Tese (Doutorado) - Escola de Veterinária, Universidade Federal de Minas Gerais, Belo Horizonte.

SIQUEIRA, R.S. Manual de microbiologia de alimentos. Brasília, D.F: Embrapa, 1995. 154p.

SMITH, H.W. Antibiotic-resistant bactéria in animal: the danger to human helth. Br. Vet. J., v.130, p.110-119, 1974.

SOUZA, C.S. Uma guerra quase perdida. Rev. Ciên. Hoje, v.23, p.27-35, 1998.

TAVARES, W. Bactérias gram-positivas problemas: resistência do estafilococo, do enterococo e do pneumococo aos antimicrobianos. Rev. Soc. Bras. Med. Trop., v.33, 2000. Disponível em: < http://www.scielo.br/pdf/rsbnt/v33n3/2477.pdf $>$. 